\title{
Interpreting the Construction of the Multimodality of E. E Cummings' "Eccentric Typographical" Poem "l(a"
}

\author{
Duxin $\mathrm{Cao}^{*}$ \\ College of International Studies, Southwest University, China \\ Liwei Chen \\ College of International Studies, Southwest University, China
}

\begin{abstract}
Kress and Van Leeuwen, who introduced the meta-function into visual circumstances and established the Grammar of Visual Design which is developed from the theoretical framework of Halliday's systemic functional grammar and provides a theoretical foundation for researches on multimodality, holds that not only verbal semiotics but also visual semiotics can express meaning. Therefore, based upon the theory of systemic functional grammar and the theory of multimodal discourse analysis, this paper takes E. E cummings' poem "l(a" as an example and attempts to propose a model of multimodal approach to visual poems. The particular focuses of the study are laid on interpreting the construction of its verbal modality which includes the ideational metafunction, interpersonal metafunction and textual metafunction, and the construction of its visual modality (typographical aspects) which includes the establishment of visual grammar systems and the ways the grammatical structures of visual modality realize representational metafunction, interactive metafunction and compositional metafunction so as to explore different possibilities of interpreting the poem. It is proved by the study that multimodality approach proves a systemic and more through way in interpreting such poems. Meanwhile, it further verifies the fact that multimodal analytic approach to discourse integrates language and language-related resources, with the result of making the discourse interpretation more comprehensive and approximative. Hopefully, the provoking result of this study will inspire further studies on multimodal approach to visual poetry.
\end{abstract}

Index Terms - visual poetry, typography, multimodality discourse analysis, metafunction

\section{INTRODUCTION}

\section{A. Research Background}

Visual poetry is poetry or art in which the visual arrangement of text, images and symbols is important in conveying the intended effect of the work (Dong Chongxuan, 2004). In other words, Visual poetry is a medium that explores the tension that lies between the semantics and the visuality of written language, and treats words, letters or symbols as primary material, enriched by the dynamic nature and physical possibilities of technology. It is sometimes referred to as concrete poetry, a term that predates visual poetry, and at one time was synonymous with it. Visual poetry was heavily influenced by Fluxus which, a name taken from a Latin word meaning "to flow", is an international network of artists, composers and designers noted for blending different artistic media and disciplines in the 1960s and thus is usually described as being Intermedia (O'Dell \& Kathy, 1997). Intermedia work tends to blur the distinctions between different media, and visual poetry blurs the distinction between art and text. Whereas concrete poetry is still recognizable as poetry, being composed of purely typographic elements, visual poetry is generally much less text-dependent. Visual poems incorporate text, but the text may have primarily a visual function, for it often incorporates significant amounts of non-text imagery in addition to text.

\section{B. Literature Review}

Visual poetry has been widely studied at home and abroad and opinions about it have differed among traditional literary critics, which can be recapitulated and classified into following aspects:

(a) literary criticism: to explore the forms, skills, language, words and titles of these visual poetry (Zhang Shuyuan 2003; Duan Jingwen 2002).

(b) narrative stylistics and rhetorics: to investigate the deviation, salience and metaphor represented in these visual poetry (Kidder 1979; Widdowson 1992; Zhao Cuilian 1994; Luo Yimim 2004).

\footnotetext{
* Supported by the Fundamental Research Funds for the Central Universities of 2014: "A Cognitive Construction Grammar Approach to English Cognate Object Constructions" (NO.SWU1409353) and the Fundamental Research Funds for the Central Universities of 2013: “An Empirical Study of the Acquisition of English Phrasal Verbs: From the Perspective of Cognitive Linguistics" (NO.SWU1309462).
} 
(c) functional stylistics: to probe into the discourse cohesion and coherence of these visual poetry (Li Bingmei 2006; Yu Xueyong 2007).

(d) phonology: to inquire into the visual speech of these poetry, namely, to define the signified of these orthographic words with the help of visual forms of the poetry (Cureton 1985b; Griffiths 1980; Funkhouser 1984)

(e) cognitive linguistics: to study the poetic effect and its underlying mechanism (Cureton 1985a; Hiraga 2005; Ren Yuxin 2008)

(f) multimodal discourse analysis: to analyse the meaning textured in these visual poetry by integrating language and language-related resources so as to overcome the deficiencies of traditional test-based analyses of these poems (Welch 1984; Leeuewn 2006; Wang Huamin 2004; Hu Dan 2007; Xin Zhiying 2008).

Based on the above-listed literature review, it is evident that these studies are limited in two aspects. First, except the multimodal discourse analysis emerging in the late 1990s, other traditional test-based analyses ignore the non-linguistic semiotic systems comprising the visual poetry. Second, though the multimodal discourse analysis overcomes the deficiencies of traditional test-based analyses, it focus on the study of film and TV, multimedia, posters and visual advertisements while the relevant study of visual poetry is still in its infancy and needs to be further advanced. Therefore, this paper takes e. e cummings' poem "l(a" as an example and attempts to explore the construction of its verbal modality which includes the ideational metafunction, interpersonal metafunction and textual metafunction, and the construction of its visual modality (typographical aspects) which includes the establishment of visual grammar systems and the ways the grammatical structures of visual modality realize representational metafunction, interactive metafunction and compositional metafunction so as to verify the fact multimodal analytic approach to visual poetry integrates verbal semiotic and visual semiotic and thus is a more thorough way in interpreting such poems, for it makes discourse interpretation more comprehensive and approximative.

\section{TyPOGRAPHY AS A SEMIOTIC MODE}

\section{A. Modality, Multimodality and Multimodal Discourse}

Modality refers to the channel and medium by which signs are transmitted (oral, gesture, written) and includes the semiotic systems of language, image, color, music and so on (Zhu Yongsheng 2007). Multimodality seamlessly combines graphics, text and audio output with speech, text, and touch input to deliver a dramatically enhanced end user experience (Li Zhanzi 2003). When compared to a single-mode of interface in which the user can only use either voice/ audio or visual modes, multimodal applications gives them multiple options for inputting and receiving information. This makes the service application much easier to use or more intuitive. Kress (2001) pointed out that all modalities are meaning potential. Mutimodal discourse is a kind of "new writing" in which different modalities interact with and complement each other to create meaning in context (Yang Xinzhang 2009). After getting a general idea of mutimodal discourse, we move onto the following questions: how should we analyze it ? What is its theoretical foundation?

\section{B. Multimodal Discourse Analysis: A Systemic Functional Exploration}

Kress and Van Leeuwen (1996) in their book Reading Images: The Grammar of Visual Design, used Halliday's metafunctional theory (Halliday, 1978) to argue that the image constitutes a semiotic mode in its own right, a kind of "language". According to Halliday (1985), spoken and written texts always and simultaneously fulfill three broad communicative functions or "metafunctions", and specific linguistic resources, specific lexicogrammatical and discourse-level "systems" can be matched to each of these three metafunctions--the ideational, the interpersonal, and the textual functions. Kress and Van Leeuwen (2006) proposed that images, too, can fulfill all three of these metafunctions, and that the "grammatical" resources of images, too, can be matched to specific metafunctions.

To briefly gloss the metafunctions, the ideational function is the function of constructing representations of what is going on in the world and in our mind. The most important linguistic systems which realize it, are the lexicon and the grammar of transitivity, which outlines the different kinds of processes (e.g. material and mental processes) that make it possible to create different representations of what must ultimately be the same phenomena. In images, Kress and Van Leeuwen argued, this function by the name of "representational metafunction", which includes "narrative representations" and "conceptual representations" is fulfilled by certain aspects of composition (e.g. Kress \& Van Leeuwen, 1996, pp.79-89) and by systems of vectoriality (Kress \& Van Leeuwen, 1996, pp.56-71).

The interpersonal function is the function of language to constitute social interactions and express attitudes towards what is being represented. One of the lexicogrammatical resources for the former is the grammar of mood, which allows us to do different things with language, such as making statements, asking questions and so on. The linguistic resources for expressing attitudes have recently been formulated in the theory of "appraisal" systems (Martin, 2000). In images, the interpersonal function by the name of interactive metafunction is fulfilled by the systems of the gaze, size of frame, and angle (Kress \& Van Leeuwen, 1996).

The textual function, finally, allows us to use language to reorganize individual representations-cum-interactions into coherent texts and communicative events, linguistically through the systems of cohesion, thematic structure, and given-new information. In images, the textual function by the name of compositional metafunction, is fulfilled through the systems of composition, framing and salience (Kress \& Van Leeuwen, 1996).

In this part, the author has outlined the theoretical framework of multimodal discourse analysis but a question arises: 
can typography--a main device employed in visual poetry, fulfill all three of these functions?

\section{The Multimodality of Typography}

As to the question alluded in the last part, Kress and Van Leeuwen (1996) give an answer of affirmation. In their eyes, typography can, and is, used ideationally, to represent actions and qualities, which means to perform representational function of visual images. Typography can also enact interactions and express attitudes to what is being represented, namely the interactive function of visual images. A word can be changed into a "warning" or a "question" through typography, and typography can also be used to express attitudes towards what is being represented. It can interpret, or, you might say, "perform" texts, or parts of texts, as modern, or traditional, capricious or serious, exciting or dull and so on.

The way typography can realize textual meaning, that is to say, the compositional metafunction, is verified by the fact that typography can demarcate the elements, the units, of a text and express their degree of similarity or difference as textual elements, and it can foreground key elements of a text and background less important elements. Many typographical signs that are not letter forms realize textual meaning, the most obvious example being punctuation marks greatly exemplified in Cummings' visual poetry, and they, too, are now rapidly developing new uses and new signs.

Kress and Van Leeuwen introduced meta-function into visual circumstance and establish the grammar of visual design, which provided a theoretical foundation for researches on multimodality. Therefore, based upon the theory of systemic functional grammar and the theory of multimodal discourse analysis, this paper takes E. E cummings' poem "l(a" as an example and attempts to propose a model of multimodal approach to visual poems.

\section{E. E CUMmings AND His UNIQUe POETIC Forms}

\section{A. A Brief Biography of E. E Cummings}

According to Kennedy (1980) and Chang Yaoxin (2001), Edward Estlin Cummings (October 14, 1894 - September 3 , 1962), popularly known as E. E. Cummings, with the abbreviated form of his name often written by himself in lowercase letters as e.e. Cummings, was born in Cambridge, Massachusetts, to liberal, indulgent parents who from early on encouraged him to develop his creative gifts. While at Harvard, where his father had taught before becoming a Unitarian minister, he delivered a daring commencement address on modernist artistic innovations, thus announcing the direction his own work would take. He began to write avant-garde poems in which conventional punctuation and syntax were ignored in favor of a dynamic use of language. Cummings also experimented with poems as visual objects on the page. These early efforts were included in Eight Harvard Poets, a collection of poems by members of the Harvard Poetry Society (http://www.poetryfoundation.org/). As well as being influenced by notable modernists including Gertrude Stein and Ezra Pound during his years at Harvard, Cummings' early work drew upon the imagist experiments of Amy Lowell, which characterizes the use of visual images to represent the content of poetry.

After graduating from Harvard, Cummings spent a month working for a mail order book dealer and then left the job because of the tedium. In April of 1917, with the First World War raging in Europe and the United States not yet involved, he volunteered for the Norton-Harjes Ambulance Service in France. Here he and a friend were imprisoned (on false grounds) for three months in a French detention camp. At the end of the First World War Cummings again went to Paris to study art. His visits to Paris exposed him to Dada and surrealism, which in turn permeated his work. Generally self-taught, he considered himself a professional painter throughout his life. In the late 1920s, however, Cummings settles into a more representational, subjectivist mode of painting and notably breaks with the aesthetics of "objectivity, calculation and detachment" (Cohen, 1987). His goal was to stay connected to reality to a greater extent than the abstract art movement cared to. In fact, all of his works, even the colorful cubist abstractions and suggestive impressionist portraits, display his positive commitment to experience and a direct tie to it. As he himself claimed "The day of the spoken lyric is past... The poem which has at last taken its place does not sing itself; it builds itself, three dimensionally, gradually, subtly, in the consciousness of the experiencer" (http://www.anb.org/articles/16/16-00394.html). His paintings hold onto the inner dynamism of the experience he wants to relate, while his poetry is informed by images, colors, and shapes. He never draws a distinct line between poetry and painting, both of which stream from the same creative source, as he sees it.

\section{B. Unique Poetic Forms of E. E Cummings}

Among the most innovative of twentieth-century poets, according to Chang Yaoxin (2001) and Peng Yu (1995), E. E. Cummings experimented with poetic form and language to create a distinct personal style. He has been known for his unusual way of lines distribution and outstanding writing skills. He resorted to various unique syntactic structures in many of his poems to create his unique "eccentric typography". Many of them do not only involve graphological or punctuation innovations, but also syntactic ones.

\section{Multimedia and Multisensory}

E. E. Cummings is an artist as well as a poet who blurs the line between the two forms of art. His synesthesia inoculates him against postmodern disintegration of meaning or form. He rebels against traditional poetic forms and invents a new language of multisensory and multimedia processing. He makes orthography and page design sculpt the spontaneous experience he wants to convey ( Nikitina, 2009). 
His "twin obsessions" with poetry and painting make him unique innovators even in the age of wild and ubiquitous experimentation of the early twentieth century (Kidder, 1979). He stands out because his bold demolition of traditional poetic forms did not lead to disintegration of meaning or self-absorbed formalism. This happened because his "poempictures" and the merger of the visual and verbal sensibilities led to the "hardening" of his image making and inoculated it against postmodern deconstruction (Cohen, 1987). He crossed the line from painting to poetry on a daily basis and deployed the kind of explosive under the foundation of conventional poetic rhyme and line. He found in himself the power to celebrate births not burns, life not language, experience not experiment. His drive for unity of form and content, the visual and the verbal, is present in all his works, because he "not only thought and heard his poems, but saw them as well" (Cohen, 1987).

A union of the verbal and the visual delivers "the emotional substance of experience" in all its vitality and integrity (Lane, 1976). Convergence of different media is attempted in his works not as a formal exercise, but as a way to reinforce the message and protect it from disassembly. In translating across media, he distilled and solidified the essence of the image, making it signify, for he hoped for a true convergence of media and perception, "in which the artist and viewer actually become the work of art — presumably, by imaginatively entering into it so thoroughly as to obscure the boundaries separating subject and object" (Cohen 70).

Merging media is a strikingly contemporary idea that is being realized actively in interactive media where the path to the integrity of meaning seems to lie through synesthesia. Cummings put the sound, rhythm, color to work to overcome the analytical flatness of the poetic message. Poem-crafting in his hands involved tinkering with words as if they were also musical bars or design elements with which to give shape to experience. Their synesthetic sensibility - bringing the verbal and the visual together — possibly inoculated Cummings, in particular, "against the galloping stagnation which seems to carry off so many of our younger American poets" (Slater Brown , 1984).

\section{Formal Innovations}

The breaks that proved much more positive and productive for E. E. Cummings were his formal innovations. These innovations involved radical rethinking of all poetic material: words, their connections to other words, and their placement on the page as semantic devices. Such breaks signal a new relationship between the poet and his material, informed by a sensibility of a visual artist. The poet treated a word as a unit of meaning as well as a design piece. The visual aspects of the word expressed through its graphics and placement on a page are not extraneous to meaning, but an essential part of it.

Several linguistic innovations includes word-making, loosening of syntactic ties, line and orthography breaks. As Perkins (1987) claimed, "He experimented with the ellipsis, distortion, fragmentation, and a grammatical juxtaposition that make some of his poetry difficult. He dismembered words into syllables and syllables into letters, and though his fragmentation activated rhymes and puns, the reasons for it were also typographical--the look of the poem on the page"

The poet is also a tireless word-maker. He created words by merging several stems into compounds ("shout-lipped," "puddle-wonderful," "mud-luscious"), by moving the words between grammatical categories (a noun becomes a verb, an adjective becomes an noun), and by turning an abstract concept into countable nouns.

He also practised the loosening of logical and linguistic ties between words in the sentence. Loosening of syntactic ties and the use of associative logic in such poetry grant words more stylistic, graphic and semantic independence, turning them into "individual syntactic values" (Vinokur, 1967), which would be hard to single out if words were tightly bound in grammatical constructions. Cummings achieved the effect in dissolving bonds between the words and even letters and playing them out as single notes carrying their own color, rhythm, and pitch.

His formal innovations look like clean breaks from tradition, without any precedent. On a deeper level, however, his linguistic sensibility, informed by visual thinking, could be seen as a return to the ancient conception of a word as an ideogram -a sign, which blends the visual and the verbal and bridges the gap between the signifier and the signified. His kind of "linguistic creativity is traditional but not in the sense of direct borrowing from these or those close or remote cultural traditions, but in the sense that it serves as a constant reminder of the origins of this linguistic culture" (Vinokur, 1967). In the very act of breaking words and lines apart, Cummings restored language to its original holism based on the fusion of the verbal and the visual, which got severed with time. This explains why his poetry is best experienced visually and orally, as speech and image, not text.

These bold experiments in the deviant poetic language have become one of the focuses of the linguistic study. Linguists attempt to analyze his poems from different linguistic perspectives.

Based upon the theory of systemic functional grammar and the theory of multimodal discourse analysis, this paper takes E. E cummings' poem "I(a" as an example and attempts to propose a model of multimodal approach to visual poems. The particular focuses of the study are laid on interpreting the construction of its verbal modality which includes the ideational metafunction, interpersonal metafunction and textual metafunction, and the construction of its visual modality (typographical aspects) which includes the establishment of visual grammar systems and the ways the grammatical structures of visual modality realize representational metafunction, interactive metafunction and compositional metafunction.

\section{On the Construction of Multimodality of E. E Cummings' "L(A"}




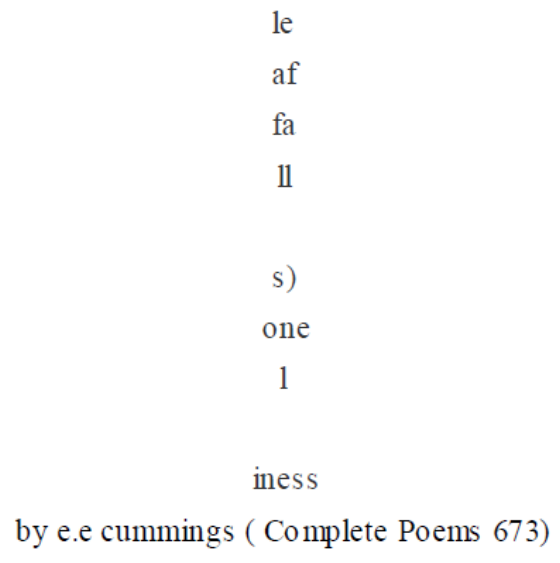

This is not an arbitrary construct, though at first glance it may appear to be. What Cummings did was to take the word loneliness, break it in two, and insert a short sentence, a leaf falls, into the break; thus, the sentence is "parenthesized" by the word. Not satisfied, however, with merely saying, in effect, "loneliness: a leaf falls," Cummings further disguised his sentiment by applying the schema of dispersion: scattering the lines of the original according to some pattern different from its original structure, perhaps breaking it up into lines that are really phrases or a few words, or by breaking lines in half at the caesurae, or by enjambing two or more lines. This haiku-like poem has been described as the "most delicately beautiful literary construct that Cummings ever created" (Kennedy, 1980). Consisting of just four words, which the poem splits into two distinct phrases — "loneliness," and "a leaf falls"—-the poem has generated a wide range of critical analysis. The connection between the two phrases seems at first tenuous. The falling of a leaf is a concrete act, whilst the word "loneliness" is an abstract concept. However, conventional criticism has made the link. Rushworth Kidder (1979), who described the poem as a "brief description of autumn," states that "the single leaf falling is a metaphor for both physical and spiritual isolation". Barry Marks (1964), in a highly detailed reading, asks the reader to hold the two phrases simultaneously together so that various possibilities emerge. Thus, "Loneliness is like a falling leaf," or "The feeling of loneliness is the feeling a man gets when he watches a single leaf falling." Marks (1964) concludes that "It does not take much ... to ... think of autumn, the end of the growing season, the death of the year". Autumn (fall) and the autumn of a man's life — death is a lonely business (http://www.gvsu.edu/).

Such speculation is interesting indeed, but to the critics, not the point of the poem - "it [the poem] asks us to look at the printed page" (Marks, 1964). The form of the poem does indeed foster an attitude of internalisation, of drawing attention to itself as an artifact, a work of art.

\section{A. On the Construction of Verbal Modality}

Consisting of just four words, which the poem splits into two distinct phrases_— "loneliness," and "a leaf falls"—-the poem has generated a wide range of critical analysis. The connection between the two phrases seems at first tenuous for it can be reorganized into two different compositional structures. Firstly, it can be rearranged into: "a leaf falls in loneliness". The word "in" does not exist in the original manuscript, but given the peculiar visual effect of the punctuation mark: parentheses, we paraphrase it into its counterpart "it". Secondly, it can also be considered as two independent clauses: 1) a leaf falls; 2) loneliness, with the second clause as an elliptical sentence.

To begin with, we will analyse the first combination from the perspective of Halliday's systemic functional grammar, namely "a leaf falls in loneliness". As to its ideational function, this clause contains a material process, which was represented by the verb "fall" and this process has a participant (namely, actor) "a leaf" and a circumstantial element "in loneliness". With regards to its interpersonal function, this clause is in indicative mood and in this way the readers get the impression: "A leaf falls alone, and no one cares or notices except the narrator". The textual function of this clause is embodied in the way that "a leaf" function as both the theme and the departure of information, and "falls in loneliness" as the rheme or the new information.

Then we move onto the analysis of the second combination: 1) a leaf falls; 2) loneliness. The ideational function of the clause "a leaf falls" is fulfilled still by "a leaf" functioning as an actor in the material process and the interpersonal function still embodied by its indicative mood, so this is same with the first combination. However, the difference lies in the textual function. In the second combination, we regards "loneliness" as an elliptical sentence with the element "it is" omitted rather than a circumstantial element and in this way the clause "loneliness" is loaded with much more meaning and emotion than just functioning as a circumstantial element. As Huang Guowen (2006) claimed, a clause usually describes a situation which can express both dynamic meaning and stative meaning. So the clause "it is loneliness" in the second combination, can convey, dynamically, the meaning "a leaf is falling" on the one hand, and statically, the 
unified and grave loneliness brought about by the scene of "a falling leaf" and the evoked meditation of life. When we integrate the two combinations to interpret the poem, we can get the impression that not only the leaf is in loneliness but also the narrator is also in loneliness and this interpretation can also be verified by the analysis of its visual modality which will be shown in the following parts.

\section{B. On the Construction of Visual Modality}

\section{The Construe of Representational Meaning}

In images, Kress and Van Leeuwen argued, "representational metafunction", which includes "narrative representations" and "conceptual representations" is fulfilled by certain aspects of composition and by systems of vectoriality. Based on this theory, this part will analyse the representational meaning of this poem from the perspective of alignment of type, word-spacing and line-spacing, which is detailedly shown in the following parts.

\subsection{Alignment of Type: Vertical Linear}

To begin with, the poem dribbles down the page, at once suggesting the descent of a falling leaf, whilst also visually resembling the figure " 1 ", or a vertical stroke on a page. The reader's progress is slowed down by the shattered syntax, and the reader's eye is forced into a similar movement as that when watching a descending leaf, both finally coming to a rest on the "ground" ("iness" - the longest and last line).We see that the poem is organised into stanzas of alternating lines of 1-3-1-3-1, whilst the first four lines alternate vowels and consonants, both indicating, perhaps, the twisting motion of the leaf as it falls. The downward movement is enhanced by lines 5 ("ll") and 8 ("l"), which can be seen as visually enacting the journey. Without even reading the words and using fields of representation perhaps unusual in poetry (the visual in this case), the reader is drawn toward one of the main themes of the poem-that of "one-ness or loneliness", which is consistent with the proverb " A picture paints a thousand words". Thus, "Loneliness is like a falling leaf," or "The feeling of loneliness is the feeling a man gets when he watches a single leaf falling." It is no surprise that this poem was the first poem in Cummings' book 95 Poems and was numbered "I", further impressing the main theme upon the reader.

\subsection{Word-Spacing: Deconstruction of Words}

It is once the reader begins to read the poem that the form becomes vital. Starting with the first line, we see that the letter " 1 " is the same character on the typewriter keyboard as the number "1." Thus, moving into another field of representation (the numerical), we see the number one repeated throughout the poem. Furthermore, the next letter "a" is the indefinite article and its singularity at once supports the concept of "loneliness" and "one-ness." However, pushing into yet another field of representation, this time the French language (Cummings at least has a acquaintance with French for his stay in Pairs during World War I), we see that "la" is the French equivalent of "a" as well as a singular article. Immediately following this comes: "le," at once another "one" (the "l") and also another singularity (this time male - as if even the sexes are separated). Lines three and four enact the twisting of the leaf as it is seen from different sides. Line five repeats the "one-ness' motif (ironically in a pair) as well as visually enacting the downward movement of the leaf. Line six indeed, has a sonic level. It is full of soft sounds and sibilances: it makes a moaning, windy noise, and the esses sound like leaves rustling along the ground, strengthening the dismal mood of loneliness. Line seven explicitly states "one," whilst line eight numerically does the same. Finally, line nine, "iness," can be interpreted as "I-ness', (remembering that Cummings always used the lower-case "i" to represent "I") or "one-ness."

Meaning is thus enhanced by the overlapping fields of representation, promoting a kind of unification of meaning - a "one-ness." Yet the closer we examine the poem the more the concept / numeral "one" is shown to be both fragmented and multiple. Thus, the themes of "one / singular / alone" are only perceptible, paradoxically, through the diverse, and shattered syntax. The "I / 1" is, literally, seen to be many "1's" at the same time.

Furthermore, the very arrangement, while seemingly arbitrary, contains its own order and functions to reinforce the content of the poem. Specifically, the disconnected aspect of the poem in terms of its arrangement amplifies the theme of loneliness. Dilworth (1996) in his examination of the poem remarks that "the image of the falling leaf gives narrative definition to the concept loneliness". A leaf falls alone, and no one cares or notices except the narrator. Besides, since "falls" extends from stanzas two, through three, and into four just as "loneliness" starts in stanza one, skips two, moves through four, and finishes in stanza five, the phrasing of these passages paradoxically produces a continuously fragmented commentary on loneliness. This arrangement also suggest that what may binds us to one another, again paradoxically, is the possibility that ultimately we are each alone (http://www.etd.lib.fsu.edu/).

\subsection{Line Spacing: Formation of Stanzas}

We see that the poem consisting of just four words, which the poem splits into two distinct phrases — "loneliness," and "a leaf falls", is organised into five stanzas of alternating lines of 1-3-1-3-1, and seemingly recounts the life stages of a leaf during the year, which metaphysically links "a leaf falls" with the "autumn" years of a person's life. As Marks (1964) concludes that "It does not take much ... to ... think of autumn, the end of the growing season, the death of the year". Autumn (fall) and the autumn of a man's life - death is a lonely business.

In the beginning, the line "l(a" symbolizes that the leaf has just sprouted with brightly green freshness, and then lively and dynamically, nod and smile to us as indicated by the lines two "le", three "af" and four "fa". However, as soon as the leaf turns out and grows, you know that summer is near. In the season of relentless sun and oppressive heat, the leaf gradually loses its freshness and vitality and stops swaying in the wind, and temporarily retracts to rest, conforming to the visual image of line five "ll". When autumn (fall) comes, the leaf struggles to clinch to the branch but the cold 
and bleak breath of autumn still blows it away, leaving it floating up and down in the air, which is the right visual reflection of lines "s)" "one" and "l" . Finally, when the cold winter approaches, the leaf also reach its final stage of life and rests on the "ground" as is explicitly represented by the line nine "iness"--a state of "grave" loneliness. So the device of line-spacing here vividly show us the life journey of the leaf and this also can also make us associate the "a leaf falls" with the "autumn" years of a person's life--there death is also a lonely business.

\section{The Construe of Interactive Meaning}

In images, Kress and Van Leeuwen argued, "interactive metafunction is fulfilled by the systems of the gaze, size of frame, and angle. Based on this theory, this part will analyse the interactive meaning of this poem from the perspective of spatial configuration and letter fit, which is detailedly shown in the following parts.

\subsection{Spatial Configuration: Visualization of Blank}

In the original printing of 95 Poems (1958), "l(a" appeared opposite a blank page - thus at once suggesting the loneliness explicit in the poem. The twenty-three characters (including the title) seemed lost, overwhelmed by the white space, and one's eyes are automatically drawn to the fragile construction. Metaphorically, then, the poem enacts the vastness of space and the smallness of man within that space. This has existential undertones and implicitly suggests another theme of the poem - that of death (autumn). Compared with the unmeasured vastness of the universe, the mankind is extremely small and insignificant, just like the falling leaf in the bleak autumn. Being poor or rich, great or negligible, no one can escape the destiny of human beings--death.

\subsection{Letter Fit: Decapitalization}

In this poem all the letters are in lower-case even where it should be capitalized. Perhaps, this is Cummings' way of protesting. He was a strong believer in equality and the rights of all people. He wanted to show that we are all equal not just as people but also in our names. Even to the point that every "letter" was equal, and that no letter should carry more weight than any other letter. He even wrote his own name in lowercase letters as e.e. cummings and always used the lower-case " $\mathrm{i}$ " to represent "I". Therefore, by having all letter lowercase and using no uppercase, he was demonstrating equality with no superiority. Furthermore, this also implies his modesty and humility towards the universe. As mentioned in the last part, compared with the unmeasured vastness of the universe, the mankind is extremely small and insignificant just like the falling leaf in the bleak autumn. Being poor or rich, great or negligible, no one can escape the destiny of human beings--death. This renders us the enlightenment or apocalypse of an important rule of life--the universe is eternal while the human life is transient, resulting in the unavoidable but futile sense of loneliness towards life.

\section{The Construe of Compositional Meaning}

In images, Kress and Van Leeuwen argued, compositional metafunction is fulfilled through the systems of composition, framing and salience. Based on this theory, this part will analyse the compositional meaning of this poem from the perspective of ornamentation devices, namely parentheses which is detailedly shown in the following parts.

Punctuation, Levenston (1992) teaches us, is a physical aspect of the text, and together with other physical aspects as typeface, layout, and spelling, participates in the creation of meaning, and "provides additional information not directly available from the flow of speech". Punctuation researchers have identified two prototypical functions. The first, traced by Naomi Baron (2001) back to Aristophanes around $200 \mathrm{BC}$, is assisting the reader to recreate an original oral rendition of the text, as in marking for the reader varying lengths of pause for when the text is to be read aloud. This role affirms an affinity between marks of punctuation and spoken language. The second, more uniquely associated with the written text, is that of clarification of meaning and organization of units, particularly through marking syntactical relationships.

Some have recognized the significance of punctuation in poetry: punctuation as a poetic device. Punctuation in poetry, especially in free-verse poetry, is "a matter of artistic choice" writes Alan Golding (1981). For Alan Helms (1980), "far from operating as a peripheral part of a poet's work," punctuation "is central to our understanding of poetic meaning because of its ability to influence prosody". "The unorthodox use of punctuation to increase the expressive complexity of literary texts still awaits its historian" says Gerald Janecek (1996).

So, it would come as little surprise, then, that in accordance with his penchant for linguistic estrangement, typographical play, and the creation of movement and experience, Cummings found punctuation a particularly rich arena. As available linguistic material and poetic repository, Cummings made full use of the entire range of semantic, physical, and conceptual contexts punctuation participates in creating. And among the various punctuation marks none has been more explored, used, and abused by Cummings than parentheses. Cummings is the unparalleled poet of parentheses, and the parentheses are for Cummings an extraordinarily prized poetic device, granting us a unique test case of punctuational appropriation.

In Cummings' poems, parentheses provide a dual status to the material in them: it is part of the whole text (it is on the same page and part of the same poem) but also separate. The separation is not complete or total, and this allows for many interesting manipulations which will hinge upon the question of textual autonomy: how independent is the parenthesized material and how dependent? In this most famous poem "1(a" , the parentheses is not used to create a protective shield around delicate content or to signal a part of the text for subordination or superordination. Rather, they are used to interlink two different sections of the text, causing them to exist simultaneously in isolation and in interaction. It is exactly this tension between their making sense separately and being typographically as well as 
thematically intertwined that is at play here, like two parts melted into each other, or two layers of the same poem (http://www.engl.niu.edu/), and that fulfills its textual metafunction or compositional metafunction.

\section{CONCLUSION}

Visual poetry, an art creating visual images through words, is a special literature form combining poetry and painting. Kress and Van Leeuwen, who introduced the meta-function into visual circumstances and established the Grammar of Visual Design which is developed from the theoretical framework of Halliday's systemic functional grammar and provides a theoretical foundation for researches on multimodality, holds that not only verbal semiotics but also visual semiotics can express meaning. Therefore, based upon the theory of systemic functional grammar and the theory of multimodal discourse analysis, the writer proposes tentatively a model of visual grammar approach to visual poems and takes E. E Cummings' most famous poem "l(a" as an example to investigate the construction of its verbal modality which includes the ideational metafunction, interpersonal metafunction and textual metafunction, and the construction of its visual modality (typographical aspects) which includes the establishment of visual grammar systems and the ways the grammatical structures of visual modality realize representational metafunction, interactive metafunction and compositional metafunction so as to explore different possibilities of interpreting the poem. It is proved by the study that the visual modality plays such an important role in constructing the meaning of the poem that it can never be neglected and only through combing the verbal and visual modality together, can we reach the full potential meaning of the poem or make the discourse interpretation more comprehensive and approximative. Hopefully, the provoking result of this study will inspire further studies on multimodal approach to visual poetry.

\section{REFERENCES}

[1] Baron, Nomi S. (2001). Commas and Canaries: The Role of Punctuation in Speech and Writing. Language Sciences 23(1): 15-67.

[2] Brown, Slater. (1984). Review of Tulips and Chimneys. In Guy L. (Eds.), Rot Critical Essays on E. E. Cummings. Boston: G. K. Hall: 38-39.

[3] Chang Yaoxin. (2001). A Guide to a Survey of American Literature. Tianjin: Nankai University Press.

[4] Cohen, Milton A, (1987). Poet and Painter: The Aesthetics of E. E. Cummings' Early Work. Detroit: Wayne State UP.

[5] Cureton, R. D, (1985a). Poetry, Grammar, and Epistemology: The Order of Pronominal Modifiers in the Poetry of e. e. Cummings. Language and Style, 1, 16-25.

[6] Cureton, R. D. (1985b). Visual Form in e. e. Cummings: No Thanks. Word and Image, 3, 45-56.

[7] Dilworth, Thomas. (1996). "Cummings' 'l(a"'. Explicator: 171-73.

[8] Dong Chongxuan. (2004). The Reason of Visual Poetry. Taibei: Zhongxing University press.

[9] Duan Jingwei. (2002). A key to the interpretation of E. E. Cummings' Poems. Foreign Literatures 22 (4), 96-102.

[10] Funkhouser, L \& O' Connell, Daniel C. (1984). Cummings Reads Cummings. Language and Literature, 9, 125-136.

[11] Golding, Alan. (1981). Charles Olson's Metrical Thicket: Toward a Theory of Free-Verse Prosody. Language and Style 14: 64-78.

[12] Griffiths, P. (1980). Cummings, e. e, The New Grove Dictionary of Music and Musicians. London: Maomillan.

[13] Halliday, M. A. K. (1978). A Language as a Social Semiotic. London: Arnold.

[14] Halliday, M. A. K. (1985). An Introduction to Functional Grammar. London: Arnold.

[15] Helms, Alan. (1980). The Sense of Punctuation. Yale Review 69 (2): 175-96.

[16] Hiraga, M. K. (2005). Metaphor and Iconicity: A Cognitive Approach to Analyzing Texts. Chippenham \& Eastbourne: Antony Rowe Ltd.

[17] Huang Guowen. (2006). Linguistic Exploration in Translation Studies-Analyses of English Translations of Ancient Chinese Poems and Lyric. Shanghai: Shanghai Foreign Language Education Press.

[18] Janecek, Gerald. (1996). The Poetics of Punctuation in Free verse. Slavic and East European Journal 40 (2): 297-308.

[19] Kennedy, Richard S. (1980). Dreams in the Mirror: A Biography of E. E. Cummings. New York: Liveright.

[20] Kidder, R. M. (1979). e. e cummins --An Introduction to the Poetry. New York: Columbia University Press.

[21] Kress, G. \& Leeuwen. T, V. (1996). Reading Images: The Grammar of Visual Design. Burwood: Brown Prior Anderson.

[22] Kress, G. (2001). Sociolinguistics and Social Semiotics. London \& New York: Routledge,

[23] Lane. (1976). I Am: A Study of E. E. Cummings' Poems. Lawrence: UP of Kansas.

[24] Leeuwen, T. V. (2006). Towards a Semiotics of Typography. Information Design. 14, 246-256.

[25] Levenston, E. A. (1992). The Stuff of Literature: Physical Aspects of Texts and Their Relation to Literature Meaning. Albany: SUNY Press.

[26] Li Bingmei. (2006). Deviation and Cohesion in e. E. Cummings's Poems. Foreign Literatures 26 (2), 84-89.

[27] Li Zhanzi. (2003). Social Semiotic Approach to Multimodal Discourse. Foreign Languages Research (5) 1-8.

[28] Luo Yimin. (2004). The Pragmatic Strategies of English Poetry. Journal of Sichuang International Studies University 20 (3), 42-47.

[29] Marks, Barry A. (1964). E. E. Cummings. New Haven: Twayne.

[30] Martin, J. R. (2000). Beyond Exchange: APPRAISAL systems in English. Oxford: Oxford University Press.

[31] Nikitina, S. (2009). Innovation and Multimedia in the Poetry of cummings and Mayakovsky. Comparative Literature and Culture, 4, 26-36.

[32] O'Dell, Kathy. (1997). "Fluxus Feminus." The Drama Review. 40 (1): 43-60.

[33] Peng Yu. (1995). American Poetry of the Twentieth Centurary. Kaifeng: Henan University press.

[34] Perkins, David. (1987). A History of Modern Poetry: Modenism and After. Cambridge: Belknap Press of Harvard UP. 
[35] Ren Yuxin. (2008). A Conitive-Pragamatic Analysis of E. E. Cummings' Poems L(a. Journal of Tianjin Foreign Studies University (5), 52-57.

[36] Vinokur, H. (1967). Mayakovsky: Innovator of Language. Oxford: Oxford University Press.

[37] Wang Huamin. (2004). The Function of Non-verbal Mode in Semantic Representation. Foreign Language Research (2), 74-79.

[38] Welch, R. (1984). The Linguistic Paintings of e. e. cummings, Painter and Poet. Language and Literature, 9, 110-125.

[39] Widdowson, H. G. (1992). Practical Stylistics. Oxford: Oxford University Press.

[40] Yang Xinzhang. (2009). Multimodal Discourse Analysis and Systemic Functional Linguistics. Foreign Language Education (4), 11-14.

[41] Yu Xueyong. (2007). The Features of Textual Cohesion in E. E. Cummings' Poems. Foreign Language and Their Teaching. (3), 19-23.

[42] Zhu Yongsheng. (2007). Theory and Methodology of Multimodal Discourse Analysis. Foreign Language Research (5), 82-86.

[43] http://www.anb.org/ articles/16/16-00394.html, accessed 16/ 06/ 2013.

[44] http://www.engl.niu.edu/, accessed 16/ 05/ 2013.

[45] http://www.etd.lib.fsu.edu/, accessed 16/01/ 2011.

[46] http://www.gvsu.edu/, accessed 16/ 02/ 2012.

[47] http://www.poetryfoundation.org/, accessed 06/ 05/ 2013

Duxin Cao is an MA student in College of International Studies, Southwest University, China, majoring in English Language and Literature. His research interests are Cognitive Linguistics, Semantics, Pragmatics and Philosophy of Language.

Liwei Chen is an MA student in College of International Studies, Southwest University, China, majoring in English Language and Literature. Her research interests are Cognitive Linguistics, Semantics, and Language Teaching. 